\title{
Karakteristik pemakaian register antarpramusaji rumah makan Ayam Penyet Surabaya (kajian sosiolinguistik)
}

\author{
Elen Inderasari ${ }^{*}$, Arina Mana Sikana ${ }^{2}$, Diah Arum Hapsari ${ }^{3}$ \\ Tadris Bahasa Indonesia, Fakultas Adab dan Bahasa, Institut Agama Islam Negeri Surakarta, Indonesia \\ inderasari85iain@gmail.com, arina@gmail.com, diaharumhapsari@gmail.com \\ "Corresponding author: inderasari85iain@gmail.com
}

\begin{abstract}
Sejarah Artikel Diterima: 29 Maret 2020 Direvisi: I0 April $2020 \quad$ Tersedia Daring: 29 April 2020 ABSTRAK

Kemunculan variasi register di Indonesia saat ini berkembang pesat di seluruh sektor dunia kerja. Penelitian ini bertujuan untuk mengetahui karakeristik pemakaian register antarpramusaji rumah makan Ayam Penyet Surabaya, serta makna dan fungsi register tersebut digunakan. Metode yang digunakan dalam penelitian ini deskriptif kualitatif. Data penelitian berupa tuturan kata dan kalimat antarpramusaji rumah makan dan dokumentasi daftar menu pelanggan. Sumber data berupa tuturan lisan melalui hasil rekaman antarpramusaji dan sumber tulis dari beberapa dokumen daftar menu. Teknik pengumpulan data yang digunakan meliputi (I) sadap, (2) bebas simak bebas libat, serta (3) rekam dan catat. Analisis data yang digunakan adalah model analisis interaktif (interactive model of analysis) Milles dan Huberman. Hasil penelitian ini menunjukkan kebaruan bahwa adanya kekhasan karakteristik register antarpramusaji di rumah makan Ayam Penyet Surabaya. Kekhasan kemunculan register dapat diklasifikasikan menjadi lima macam, yaitu (I) register singkatan/akronim yang digunakan untuk mempersingkat nama menu, (2) register perubahan makna yang digunakan untuk merahasiakan kode yang ada di rumah makan Ayam Penyet Surabaya, (3) register sindiran digunakan untuk memberikan kode halus antarpramusaji, (4) register tunggal digunakan sebagai wujud kata yang keadaannya dapat berdiri sendiri tanpa perlu adanya afiksasi, (5) serta register kompleks yang keadaannya tidak dapat berdiri sendiri.
\end{abstract}

\section{Kata Kunci Sosiolinguistik, Register, Antarpramusaji, Rumah makan}

\section{ABSTRACT}

The emergence of variations in registers in Indonesia is currently growing rapidly throughout the working world sector. This study aims to determine the characteristics of the use of registers used among the waiters of Rumah Makan Ayam Penyet Surabaya as well as their meanings and functions. The method used in this research was descriptive qualitative. The research data were in the forms of speech uttered among restaurant waiters and the documentation of menu lists. The data source in the forms of verbal utterances were obtained through recording. The data collection techniques included recording, participant observation, and recording. The data analysis used interactive analysis models (Interactive Model of analysis). The results of this study indicated that there is a special registers used among the restaurant waiters. The registers found can be classified into five types, namely (I) abbreviated registers/acronyms, used to shorten the name of the menu, (2) changing registers that are used to keep the secret codes in Rumah Makan Ayam Penyet Surabaya, (3) the satire register, used to provide subtle codes among the waiters, (4) singular registers, used as a form of words whose condition can stand alone without the need for affixation, and (5) complex registers whose condition cannot stand alone.

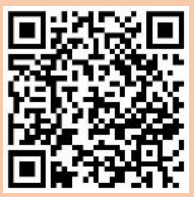

Copyright@2020, Elen Inderasari, Arina Mana S, Diah Arum H This is an open access article under the CC-BY-3.0 license

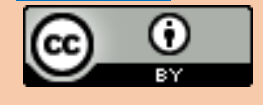

\section{Keywords Sociolinguistics, Register, Between waitresses, Restaurant}

How to Cite Inderasari, E, Sikana, A.M. \& Hapsari, D.H. (2020). Karakteristik pemakaian register antarpramusaji rumah makan Ayam Penyet Surabaya (kajian sosiolinguistik). KEMBARA: Jurnal Keilmuan Bahasa, Sastra, dan Pengajarannya, 6(I), 78-92. doi: https://doi.org/I0.22219/kembara.v6iI.II730

\section{PENDAHULUAN}

Masyarakat dalam menjalani kehidupannya tidak dapat terlepas dari bahasa, baik pada situasi resmi maupun tidak resmi, kehadiran bahasa sering tidak memandang waktu dan tempat (Hadi, 2017). Bahasa dapat diartikan sebagai piranti komunikasi masyarakat dalam upaya membina konsep diri sebagai manusia untuk beraktualisasi diri, mendapatkan kesenangan, terhindar dari tekanan, dan juga untuk keberlangsungan hidupnya (Prasetya, 2017). Bahasa dianggap sebagai media komunikasi yang dinamis, dinyatakan demikian karena bahasa dapat selalu menyesuaikan dengan aspek sosial penggunanya dan 
penggunaannya (Utomo, 20I4). Penggunaan bahasa begitu menarik karena dapat dijadikan cara atau usaha pemerintah untuk melestarikan sejarah, budaya, dan kearifan lokal yang ada pada suatu negara (Wijana, 2019). Kehadiran bahasa juga memudahkan seseorang dalam berkomunikasi guna menjembatani dalam tindak komunikasi di setiap kegiatan. Secara fungsi tradisional bahasa memiliki tiga macam, yaitu sebagai alat menyampaikan informasi, menanyakan sesuatu, memerintah, serta untuk meminta sesuatu. Ketiga fungsi tersebut umumnya dinyatakan dalam bentuk deklaratif, interogatif, dan imperatif (Tutik, Fitriani, \& Inderasari, 2020). Bahasa tidak hanya memiliki fungsi deklaratif, interogratif, dan imperatif saja, namun bahasa juga memiliki fungsi fatis. Fungsi fatis pada suatu bahasa bertujuan untuk menjaga hubungan sosial pada suatu masyarakat yang tidak bermaksud untuk menyampaikan gagasan atau bertukar berita (Widodo, 2000; Yuanita, 2019). Wujud komunikasi fatis biasanya berupa ajakan untuk memulai percakapan, ucapan selamat, ungkapan basa-basi, serta permohonan maaf dan penghormatan yang bertujuan untuk menciptakan susana yang baik dan saling memahami (Hilmiati, 2012; Rahmah, Bahry, \& Mahmud, 2017). Berbicara mengenai bahasa, Indonesia memiliki banyak bahasa di setiap daerah, bahasa tersebut tentu akan berbeda, karena setiap daerah memiliki karakteristik serta pola bahasa tersendiri, sehingga tidak mengherankan apabila bahasa suatu kelompok sosial tidak dapat dipahami oleh kelompok sosial lain. Seperti halnya bahasa pada suatu profesi akan berbeda dengan yang digunakan oleh profesi yang lain. Hal tersebut menunjukkan bahwa bahasa setiap profesi memiliki karakteristik dan pola tersendiri.

Karakteristik dalam variasi ragam bahasa berfungsi untuk mengefektifkan dan mengefisiensikan penggunaan bahasa. Fungsi pengefektifan dan pengefisiensikan bahasa juga berlaku pada penggunaan bahasa antarpramusaji di sebuah rumah makan. Pola register para pramusaji belum banyak diteliti dan dikaji dalam beberapa wujud tuturan komunikasi mereka. Kemenarikan penelitian ini sebagai wujud pengetahuan baru bentuk-bentuk register pramusaji di sebuah rumah makan untuk dapat berkomunikasi dengan baik dalam menjaga kerjasama kerja. Beberapa karakteristik register muncul sebagai bentuk bahasa baru yang memiliki kekhasan dan hanya dapat dipahami oleh komunitas sosial tertentu. Kemunculan karakteristik dan pola bahasa yang terdapat pada suatu kelompok sosial atau komunitas memicu terjadinya variasi bahasa atau yang sering disebut dengan ragam bahasa. Jika dilihat dari media dan sarana, ragam bahasa terdiri dari dua, yaitu ragam bahasa lisan dan ragam bahasa tulis. Dikatakan ragam lisan apabila sebuah bahasa dihasilkan melalui alat ucap dan yang menjadi unsur utamanya adalah fonem, sedangkan dikatakan ragam tulis apabila sebuah bahasa dihasilkan dengan media tulisan menggunakan huruf sebagai unsur utamanya (Faizun, 20I5).

Kemunculan register tidak hanya pada ragam lisan tetapi juga pada ragam tulis. Bentuk register lisan sering digunakan dalam komunikasi pramusaji baik dalam layanan pada pelanggan dan komunikasi antar pekerja di rumah makan. Bentuk register tulis disajikan dalam daftar menu pelanggan, misal register akronim PAPN, PAGN, PAPK, PAGK, dsb. Selain register akronim, adapula komunikasi sindiran yang sering muncul antarpramusaji untuk saling menyindir dan mengajak bekerja sama dalam melayani pelanggan, sehingga cepat dan memuaskan dalam melayani. Banyaknya karakteristik kemunculan register di rumah makan yang selama ini tidak diketahui masyarakat luas menjadi bahan yang menarik untuk diteliti.

Kemenarikan karakteristik mengenai keragaman bahasa dikaji dalam ruang lingkup ilmu linguistik, terkhusus pada kajian sosiolinguistik. Kajian sosiolinguistik merupakan ilmu bidang studi sosiologi yang berobjekkan kaitan antara bahasa dengan faktor-faktor sosial masyarakat (Malabar, 2015). Sumarsono (dalam Senjaya, Solihat, \& Riansi, 2018) mengatakan bahwa sosiolinguistik merupakan ilmu yang mengkaji mengenai kebahasaan yang dihubungkan dengan dengan masyarakat. Kajian ini dapat dimulai dari problem yang tengah muncul di lingkungan masyarakat dan kemudian dihubungkan dengan kebahasaannya, atau juga dapat dimulai dari sebuah bahasa yang kemudian dihubungkan dengan gejala di masyarakat. Sosiolinguistik dalam kajiannya tidak hanya terfokuskan pada karakteristik variasi bahasa, sifat khusus fungsi bahasa, dan sifat khusus pemakaian bahasa dalam suatu interaksi yang sedang dijalani serta perubahan yang terjadi antara ketiga karakteristik tersebut. Hal 
itulah yang menjadikan ragam bahasa menjadi bahasan pokok dan sangat utama pada kajian sosiolinguistik (Atmahardianto, 2012). Dengan demikian, pendekatan sosioliguistik akan selaras dengan objek kajian penelitian ini, yaitu mengenai karakteristik pemakaian register yang digunakan antarapramusaji rumah makan.

Interaksi sosial di lingkungan masyarakat atau juga di suatu kelompok masyarakat menjadi pemicu utama adanya ragam bahasa, hal ini ditandai dengan banyaknya penggunaan bahasa yang tidak seragam atau tidak sama (Setianingsih, 2013). Kemunculan ragam bahasa yang berbeda dapat terjadi karena penutur tidak hanya menguasai satu bahasa, melainkan beberapa bahasa serta penggunaan bahasa tersebut, kehadirannya disebabkan oleh adanya faktor lokasi, topik, dan partisipan (Luthfiyanti \& Kasmilawati, 2018; Ramendra, 2013). Damayanti (2018) mengatakan apabila ragam bahasa hadir guna memenuhi fungsinya sebagai sarana interaksi dalam aktivitas masyarakat yang beraneka ragam. Ragam bahasa menurut Nababan (dalam Chaer \& Agustina, 2010) akan berkaitan dengan penggunaannya yang disebut dengan fungsiolek, ragam, atau juga register. Ragam bahasa yang berkaitan dengan penggunaannya tersebut dapat mencakup mengenai kegunaan bahasa dalam suatu bidang, misalnya bidang kesastraan, pendidikan, perekonomian, atau juga perdagangan (Ardi, 2017; Giyoto, 2020). Melihat zaman yang semakin modern ini, ragam bahasa di Indonesia berkembang dengan amat pesat seiring dengan berbagai profesi dan dunia sosial yang hadir di dalam masyarakat. Hal tersebut terbukti dengan hadirnya bahasa gaul yang sering digunakan remaja, berdampingan dengan itu terdapat juga slogan, akronim, jargon, dan register.

Ragam bahasa yang perkembangannya cukup pesat tersebut, menjadikan komunikasi antar sesama menjadi lebih mudah, terlebih dalam satu guyub komunitas atau kelompok tertentu. Hal tersebut termasuk dalam klasifikasi ragam bahasa register. Register merupakan penggunaan bahasa khas yang berkaitan dengan suatu bidang, bidang tersebut dapat berupa profesi atau suatu lingkup pekerjaan. Suatu lingkup pekerjaan yang di dalamnya terdapat komunitas tersendiri, seseorang akan menggunakan bahasa-bahasa tertentu untuk keefektifan komunikas antarpengguna dalam kelompoknya. Hal tersebut dimungkinkan juga akan memunculkan fenomena yang sama jika digunakan pada lingkup pekerjaan yang lainnya. Berkaitan dengan pengertian register, Wardaugh (dalam Pramitasari, 20I4) berpendapat bahwa register adalah penggunaan kosakata tertentu yang digunakan oleh seseorang maupun kelompok sosial tertentu dalam pekerjaannya. Pendapat lain juga menyatakan hal yang sama, yaitu bahwasannya register merupakan bentuk lain dari bahasa yang mengikuti pemakainya dan umumnya digunakan oleh sekelompok masyarakat tertentu, serta berkenaan dengan pekerjaan kelompok tersebut (Firmansyah, 2017; Winanto, 2014). Antara register dan jargon memiliki hubungan timbal balik yang terletak pada istilah yang digunakan pada suatu kelompok masyarakat. Jargon diartikan sebagai istilah kelompok sosial yang memiliki pekerjaan sama atau dapat dikatakan satu profesi dan istilah yang digunakan bersifat umum, sedangkan register adalah bahasa yang digunakan kelompok sosial pada situasi tertentu dengan ciri khusus yang menyertainya, yaitu leksikogramatis, penanda fonologis sebagai tanda register yang dimaksud, ciri penunjuk, pemilihan pola sintaksis dan retorika khusus, penanda gramatis tertentu, penggunaan istilah, idiom serta penentuan gaya bahasa (Eriyanti, 2017; Mujianto, 2018; Setiawan, 2018).

Wujud register bahasa yang terdapat pada penelitian Sudaryanto (2013) mengenai register anak jalanan Kota Surakarta, ditemukan beberapa karakteristik berupa perubahan dan pergeseran makna harfiah, dominasi penggunaan bahasa Jawa, ragam bahasa informal, bentuk ringkas, dan penggunaan kata yang kasar. Selain itu, Damayanti (20I7) telah menemukan beberapa wujud register dalam penelitiannya di Polresta Pontianak, yaitu register bentuk dasar, bentuk berafiks, bentuk ulang, bentuk majemuk, pemendekan atau abreviasi, pemenggalan, singkatan, akronim, kontraksi, sapaan, kode, dan istilah khusus.

Penelitian yang relevan mengenai register dalam bahasa terdapat pada penelitian dengan judul "penggunaan register profesi bidan di klinik dan rumah bersalin di Delta Mutiara Sukodono, Sidoarjo" yang dilakukan Shahamatun (20I4). Hasil penelitian menunjukkan bahwa adanya bentuk register 
khusus yang digunakan oleh profesi kebidanan dalam melayani kelahiran (register klasifikasi kelas kata, frasa, dan singkatan) yang masing-masing register memiliki fungsi masing-masing pada pengunaannya, serta faktor penentu penggunaan register dalam profesi bidan. Perbedaan penelitian ini dengan penelitian Shahamatun (20I4), terletak pada subjek kajiannya, penelitian ini menggunakan subjek pada pramusaji rumah makan, sedangkan penelitian relevan menggunakan subjek profesi bidan kesehatan, sehingga pola temuan register pun berbeda. Penelitian relevan selanjutnya yang dilakukan oleh Hermoyo (2015) dengan judul "register pekerja terminal petikemas Surabaya". Hasil penelitian menunjukkan register atau variasi bahasa yang berhubungan dengan profesi para pekerja di pelabuhan Tanjung Perak ditandai oleh ciri-ciri tuturan (kebahasaan) mereka yang mencerminkan identitas kelompok tertentu sebagai komunitas turut. Perbedaan penelitian ini dengan penelitian sebelumnya bahwa analisis data penelitian ini menggunakan metode korelasi, yaitu metode analisis yang menjelaskan objek kajian dalam hubungannya dengan konteks situasi atau konteks sosial budaya, sedangkan untuk penelitian ini menggunakan analitis interaktif. Penelitian lain yang dilakukan oleh Inderasari \& Oktavia (2018) "pemakaian register bahasa kru bus AKAP di Terminal Tirtonadi Surakarta". Dari penelitian tersebut ditemukan dua wujud register bahasa, yaitu tunggal dan kompleks. Register tunggal merupakan pemendekan bahasa yang masih sempurna atau berdiri sendiri dan belum memiliki imbuhan sama sekali. Register kompleks merupakan bentuk bahasa yang berupa kalimat tidak lengkap atau kata yang tidak dapat berdiri sendiri. Dari penelitian tersebut, dapat dibedakan dari bentuk register yang temukan, bahwa setiap register yang dimiliki suatu kelompok tertentu memiliki wujud yang berbeda-beda, teknik pengumpulan data menggunakan simak dan catat secara langsung dengan tempat penelitian tidak terikat, sedangkan penelitian ini dilakukan terikat pada rumah makan Ayam Penyet Surabaya.

Tujuan dari penelitian ini untuk membandingkan penggunaan register yang selama ini dipakai dalam komunikasi berbagai bidang pekerjaan. Hal ini penting dilakukan guna menambah pengetahuan penulis dan pembaca mengenai variasi ragam yang digunakan dalam wujud bentuk-bentuk register antarpramusaji rumah makan. Selain itu, dengan adanya penelitian ini, pembaca akan mengetahui wujudwujud register serta makna dari register yang ditemukan. Hasil penelitian ini dapat dimanfaatkan untuk mengetahui bentuk karakteristik pemakaian register antarpramusaji pada rumah makan Ayam Penyet Surabaya, sehingga menambah variasi register dalam kebahasaan.

\section{METODE}

Penelitian ini dilakukan dengan metode deskriptif kualitatif. Metode deskriptif digunakan untuk mengumpulkan serta memaparkan terkait informasi suatu keadaan yang sedang berlangsung dengan media kata ataupun gambar, serta informasi yang dipaparkan bukanlah berupa angka-angka. Informasi yang dipaparkan berupa bentuk karakteristik pemakaian register antarpramusaji rumah makan Ayam Penyet Surabaya. Jenis penelitian yang digunakan deskriptif kualitatif dengan tujuan agar peneliti mampu mendeskripsikan data dan informasi mendalam mengenai suatu permasalahan yang akan dipecahkan (Sugiyono, 20I4). Dengan menggunakan metode ini peneliti menjabarkan suatu keadaan dengan menggunakan prosedur ilmiah untuk dapat menjawab permasalahan secara konkret. Data penelitian ini berupa tuturan register antarpramusaji rumah makan Ayam Penyet Surabaya dan dokumen daftar menu pelanggan. Sumber data dalam penelitian ini berupa tuturan lisan kata dan kalimat antarpramusaji rumah makan Ayam Penyet Surabaya. Teknik pengumpulan data menggunakan teknik sadap, bebas simak bebas libat, rekam dan catat. Teknik ini dilakukan dengan mendengarkan secara seksama dan kemudian dilakukan penyimakan terhadap sumber data tersebut. Selanjutnya bebas simak dan bebas libat dimana peneliti ikut dalam kegiatan komunikasi sebatas bebas tidak andil dalam komunikasi yang terjadi, selanjutnya yang terakhir, yaitu dengan mencatat data-data yang diperoleh dari sumber data (Subroto, 2007). Dengan menggunakan teknik simak dan catat akan lebih memudahkan peneliti, karena dapat langsung terjun ke sumber masalah. Teknik analisis data yang digunakan adalah model analisis interaktif (interactive model of analysis) (Miles \& Huberman, 1994). 


\section{HASIL DAN PEMBAHASAN}

Analisis karakteristik register dilakukan dari percakapan yang dilakukan oleh pramusaji rumah makan Ayam Penyet Surabaya. Untuk mengetahui karakteristik register pada pramusaji rumah makan Ayam Penyet Surabaya tersebut, peneliti menganalisis dari segi makna kata atau kalimat berdasarkan uraian yang menambah atau mendukung kejelasan makna tersebut.

Pembeda hasil penelitian ini dengan penelitian sebelumnya adanya kebaruan dalam bentuk kekhasan register dari masing-masing rumah makan yang digunakan antarpramusaji dan pramusaji kepada pelanggannya. Beberapa teori register dan hasil penelitian sebelumnya digunakan sebagai pendukung untuk memahami kekhasan register yang digunakan pada kelompok sosial tertentu. Dengan adanya kekhasan register pada suatu kelompok sosial khususnya pramusaji di sebuah rumah makan, membatu menambah daftar variasi bahasa yang memberikan sumbangsih dalam pengembangan ilmu sosiolinguistik.

Register sendiri merupakan suatu kode dalam bahasa yang biasanya digunakan dan dipahami oleh kelompok tertentu atau profesi, seperti register yang terjadi pada pramusaji rumah makan Ayam Penyet Surabaya. Dari analisis yang dilakukan peneliti ditemukan lima karakteristik register, yaitu (I) karakteristik register bentuk akronim, (2) perubahan makna, (3) sindiran, (4) tunggal, dan (5) kompleks.

Register akronim dapat dikatakan sebagai bahasa yang digunakan oleh kelompok tertentu dengan menggabungkan huruf atau suku kata, sehingga dalam berkomunikasi biasanya menggunakan akronim. Register perubahan makna merupakan bahasa yang digunakan oleh kelompok tertentu dalam berkomunikasi dengan adanya perubahan dari makna aslinya. Misalnya kata baru diartikan sebagai sesuatu yang belum lama dibeli, namun dalam sekelompok orang itu mengartikan kata baru dengan makna lain. Berbeda lagi dengan makna register sindiran, perkataan ini memang ditujukan untuk menyindir seseorang dalam berkomunikasi, sedangkan yang dimaksud dengan register tunggal ialah wujud bahasa yang sempurna atau dapat berdiri sendiri. Hal ini memiliki pengertian yang terbalik dengan register kompleks, karena register kompleks tidak dapat berdiri sendiri, biasanya memerlukan afiksasi. Berikut ini merupakan hasil analisis register pada pramusaji rumah makan Ayam Penyet Surabaya cabang Ngangkruk.

\section{Bentuk Register Akronim}

Register akronim merupakan wujud bahasa komunikasi yang digunakan oleh sekelompok pramusaji pada rumah makan tersebut dengan cara mempersingkat. Hal ini untuk memudahkan pelayanan antarparmusaji kepada pembeli. Data pada Tabel I merupakan register akronim yang terdapat pada pramusaji rumah makan Ayam Penyet Surabaya. 
Tabel I

Bentuk Register Akronim

\begin{tabular}{|c|c|c|c|}
\hline No & Bentuk Register & Kalimat & Makna \\
\hline I. & PAPN & $P A P N$-nya satu, ya dibungkus! & Paket Ayam Penyet Negeri \\
\hline 2. & PAGN & PAGN 5 paha semua, ya yang baru! & Paket Ayam Goreng Negeri \\
\hline 3. & PAPK & $P A P K$ dua meja 3I, ya! & Paket Ayam Penyet Kampung \\
\hline 4. & PAGK & Mbak $P A G K$-nya tiga, ya. Satu sambel matang! & Paket Ayam Goreng Kampung \\
\hline 5. & PLP & PLP satu! & Paket Lele Penyet \\
\hline 6. & PLG & Mbak PLG masih enggak, to? Masih banyak. & Paket Lele Goreng \\
\hline 7. & PNP & $P N P$-e satu, lalapannya banyak ya, meja $2 !$ & Paket Nila Penyet \\
\hline 8. & PNG & $P N G$ ada, ya. Lele masih nunggu! & Paket Nila Goreng \\
\hline 9. & GJ & Mbak ada pesanan $G J$, ya! & Gojek \\
\hline 10 & PBP & $P B P$-nya dada satu! & Paket Bebek Penyet \\
\hline II. & PBG & $P B G$-nya minta yang paha, ya Mbak! & Paket Bebek Goreng \\
\hline $\mathrm{I} 2$. & TATEGOR & TATEGOR-e satu sambele minta bawang, ya! & Tahu Tempe Penyet \\
\hline $\mathrm{I} 3$. & TATENYET & TATENYET-e dua dibungkus, ya Mbak! & Tahu Tempe Penyet \\
\hline $\mathrm{I} 3$. & TK & TK-nya satu gak pedes, ya Mbak! & Tumis Kangkung \\
\hline $\mathrm{I} 4$. & BT & $B T$-satu sambele banyak, ya Mbak! & Balado Terong \\
\hline $\mathrm{I} 5$. & $\mathrm{BP}$ & $B P$-nya setengah mateng, ya Mas gorenge! & Balado Pete \\
\hline I6. & SC & $S C$ satu sama nasi satu, ya maem sini! & Sup Ceker \\
\hline 17. & CEGOR & CEGOR-e masih nggak, Mbak? & Ceker Goreng \\
\hline $\mathrm{I} 8$. & PAG & $P A G$-nya kosong ya, cs! & Paket Ayam Geprek \\
\hline 19. & $\mathrm{NSN}$ & Ada pesenan NSN85 boks, ya jam I0.00, diambil! & Nasi Kotak Negeri \\
\hline 20. & NSK & NSK-nya paha apa dada, Fi? & Nasi Kotak Kampung \\
\hline $2 \mathrm{I}$ & NSL & NSL dimakan sini dua dibungkus, ya! & Nasi Kotak Lele \\
\hline 22. & NSB & NSB dua tanpa terong, ya Mbak! Makan sini. & Nasi Kotak Bebek \\
\hline 23. & TMP/ETM & Minume $T M P$ tiga satu gula dikit, ETM-e satu ya! & Teh Manis Panas/es teh manis \\
\hline 24 & TTP/ETT & $T T P$ satu meja I2, ETT-nya meja 2I, ya! Diantar! & Teh Tawar Panas/es teh tawar \\
\hline 25 & $\mathrm{LTP} / \mathrm{ELT}$ & $\begin{array}{l}\text { LTP-nya satu jangan diperas, sama } E L T \text {-nya dua, } \\
\text { ETM-e satu! }\end{array}$ & Lemon Tea Panas/es lemon tea \\
\hline 26. & $\mathrm{JP} / \mathrm{EJ}$ & $J P$ satu meja minta panas banget, ya Mir! EJ-nya dua. & Jeruk Panas/es jeruk \\
\hline 27. & SG & $S G$-nya satu $E B$-nya dikit aja! & Soda Gembira \\
\hline 28. & $\mathrm{AE} / \mathrm{EB}$ & $A E$ satu tambah $E B$ satu gelas, ya Mas! & Air Es/es batu \\
\hline 29. & ELS & $E L S$ satu, jangan manis-manis, ya guys! & Es Lemos Sirup \\
\hline 30. & ELBL/ELBC & $\begin{array}{l}E L B L \text { satu pesenan bukhori sama } E L B C \text { satu gak pakek } \\
\text { selasih, ya! }\end{array}$ & $\begin{array}{l}\text { Es Lidah Buaya Lemon/es } \\
\text { lidah buaya kokopandan }\end{array}$ \\
\hline $3 \mathrm{I}$ & MLS S/C/M/O & $M L S C$ satu susunya minta banyak, ya Pur! & $\begin{array}{l}\text { Milkshake } \\
\text { stroberi/coklat/melon/orange }\end{array}$ \\
\hline 32. & $\begin{array}{l}\text { Jus } \\
\text { Alp/Mgg/Tijatoje }\end{array}$ & $\begin{array}{l}\text { Jus Alp-nya satu gak pakek gula sama es batu, susunya } \\
\text { minta banyak. Kalo gak banyak dikembaliin! } \\
\text { Sementara jus tijatojenya kosong, ya! Nunggu Mas Roni } \\
\text { dari pasar dulu. }\end{array}$ & $\begin{array}{l}\text { Jus Alpukat/magga/timun } \\
\text { jambu tomat jeruk }\end{array}$ \\
\hline
\end{tabular}

\section{Peristiwa I}

Berikut merupakan salah satu contoh peristiwa percakapan antarpramusaji yang menggunakan register bahasa bentuk akronim.

\begin{tabular}{|c|c|}
\hline Pramusaji I & : "Pesanan meja 4 PAGK-dua, EJ-dua. Minta tambahan lalapan, ya!" \\
\hline Koki & : "Siap!" \\
\hline Pramusaji 2 & : "Tambahan meja 4 TK satu pedes, ya!" \\
\hline koki & : "Ditunggu!" \\
\hline Pramusaji 3 & : "Baru! Pesanan GJ, ya. PAPN tiga, ETM satu, ELBL satu, sama $S C$ satu." \\
\hline Pramusaji 2 & : "Oke, minume gojek apa?” \\
\hline Pramusaji 3 & :"TMH bungkus, ya guys." \\
\hline Pramusaji 2 & : "Siap!” \\
\hline
\end{tabular}


Pada proses komunikasi percakapan antarpelayan menggunakan narasi yang disampaikan secara cepat dan intonasi yang tegas. Percakapan tersebut dilakukan setelah pramusaji pertama melayani pembeli yang duduk di meja nomor empat. Selanjutnya tindak tutur peristiwa I tersebut dilakukan oleh pramusaji kepada koki serta pramusaji yang lain untuk memberitahu dan mengkode bahwa terdapat pesanan baru dari pembeli yang harus dikerjakan. Bentuk istilah yang digunakan ialah singkatan atau akronim. Kode singkatan atau akronim ini digunakan antar pramusaji bertujuan agar pemesanan dan pelayanan pada rumah makan tersebut cepat dan tidak bertele-tele. Hal tersebut dikarenakan dengan model pemakaian ungkapan dari akronim yang terlalu panjang tiap tipe menu, sehingga dalam upaya mempersingkat komunikasi untuk efektif dan efisien antarpramusaji. Misalnya pada bentuk akronim dari PAGK yang memiliki makna Paket Ayam Goreng Kampung, EJ yang berarti es jeruk, TK yang berarti tumis kangkung, GJ berarti gojek, PAPN berarti Paket Ayam Penyet Negeri, ETM yakni es teh manis, ELBL berarti es lidah buaya lemon, $S C$ berarti sup ceker, dan $T M H$ berarti teh manis hangat. Pengkodean tersebut juga sudah dipahami dan disepakati sejak awal antarpramusaji maupun koki. Hal ini terlihat dari jawaban koki dan pramusaji lain yang menyatakan "siap" dalam percakapan tersebut. Artinya, mereka paham atas kode pada tuturan yang digunakan.

Hal ini juga serupa dengan hasil penelitian yang dilakukan oleh Shahamatun (20I4) adanya abreviasi secara sederhana pada proses morfologis berupa pemenggalan satu atau beberapa bagian dari kombinasi sebuah huruf atau sekumpulan huruf sebagai bentuk pendek dari sebuah atau beberapa kata. Penyingkatan bisa dilakukan terhadap sebuah kata ataupun sebagai terhadap beberapa kata. Jenis singkatan dibagi menjadi dua bentuk (I) bentuk akronim dan (2) bentuk singkatan. Bentuk singkatan dan akronim tersebut digunakan perckapan sesama bidan untuk pasien. Singkatan atau akronim juga muncul pada penelitian ini pula berdasarkan data yang dituturkan antarpramusaji atau koki, tidak terjadi dengan pembeli. Fungsi kehadiran bentuk register akronim ini untuk memudahkan komunikasi antarpelayan dalam menggingat setiap menu yang dipesan pada masing-masing daftar pesanan, kecepatan layanan yang dilakukan antarpramusaji dengan koki, serta efektif dan komunikatif bahasa yang digunakan dalam berkomunikasi antarparusaji. Penggunaan register berbentuk akronim antar pramusaji dapat mengefektifkan komunikasi, sehingga pesanan dapat disampaikan dengan cepat yang akhirnya berdampak pada pelayanan yang cepat pula. Bentuk register akronim antar pramusaji rumah makan Ayam Penyet Surabaya kurang lebih terdapat tiga puluh dua register akronim. Bentuk register akronim ini banyak didapati dari hasil menu dan tuturan antar pramusaji yang ada pada rumah makan tersebut.

\section{Bentuk Register Perubahan Makna}

Register perubahan makna ialah bahasa yang digunakan antarpramusaji biasanya untuk merahasiakan kode yang ada pada rumah makan tersebut. Hal ini dikarenakan setiap perusahaan memiliki kode rahasia yang tidak boleh diketahui khalayak umum. Agar lebih memahami pengertian register perubahan makna, dapat memperhatikan Tabel 2.

Tabel 2

Bentuk Register Perubahan Makna

\begin{tabular}{ccll}
\hline No & Bentuk Register & \multicolumn{1}{c}{ Kalimat } & \multicolumn{1}{c}{ Makna } \\
\hline I. & Baru & a. Baru, ya Mbak! Meja rombongan! & a. Terdapat pesanan baru yang ditulis oleh pramusaji \\
& & b. Bim, baru! & b. Kode terdapat pembeli yang baru saja datang \\
2. & Bukhori & Ini pesenannya Bukhori, NSK totalnya 76! & Pondok pesantren Imam Bukhori. \\
3. & 22 nasi satu & 22 nasi satu, ya Kar! & Meja 22 tambah nasi satu \\
4. & Blong & Blong ayam di laci, Nduk! & Stok data pemasukan dan penjualan ayam. \\
5. & Biang & Biang sambel pesen piro, Mir? & Resep bumbu. \\
\hline
\end{tabular}




\section{Peristiwa 2}

Pada Tabel 2 sudah diklasifikasikan macam dari register akronim pada pramusaji rumah makam Ayam Penyet Surabaya. Agar lebih memahami berikut merupakan salah satu contoh peristiwa percakapan antarpramusaji yang menggunakan register bahasa perubahan makna.

Pramusaji I
Koki
Pramusaji I
Pramusaji I
Pramusaji 2
Koki
Pramusaji I
Pramusaji 3
Pramusaji 4
Kaprok
Pramusaji I
Kaprok
Koki

: "Baru, ya Mbak! Meja rombongan!"

: "Berapa, Fi jumlahe?"

: "Sepuluh orang, Mbak!"

: "Bim baru, ya tolong diorder!"

:"Oke."

: "Nanti ada pesenan Bukhori, to Fi?"

: "Iya, Mbak! Ini pesenannya Bukhori, NSK totalnya 76!"

: "22 nasi satu, ya Kart"

:"Oke."

: "Blong ayam di laci, Nduk!"

: "Ada, Mas!"

: "Biang sambel pesen piro, Mir? (Biang sambel pesan berapa Mir?)"

: "Sepuluh, Mas."

Selain register bentuk akronim, terdapat pula register perubahan makna. Kemunculan register perubahan makna disebabkan karena adanya makna baru dari kata yang sebenarnya. Seperti pada penelitian Hermoyo (2015) yang berpijak pada teori yang dikemukakan oleh Holmes (1992) bahwa ciri-ciri tuturan (kebahasaan) mereka selain akan mencerminkan identitas kelompok tertentu, juga dapat menggambarkan keadaan pemaknaan baru muncul yang sedang dilakukan oleh kelompok tersebut. Munculnya pemaknaan baru pada penelitian Hermoyo (20I5) menemukan adanya perubahan makna yang digunakan oleh para pekerja terminal pelabuhan akibat dari pengaruh pemakaian bahasa asing. Sama seperti pada data Tabel $\underline{2}$ dan tindak tutur peristiwa 2, terjadi setelah pramusaji melayani order pembeli serta menuliskan pesanan dari pembeli tersebut. Kata baru secara leksikal biasanya memiliki arti sesuatu yang belum lama; belum pernah ada; atau dimiliki. Namun pada tindak tutur peristiwa 2 kata baru pertama yang diucapkan pramusaji digunakan untuk memberitahu atau mengkode bahwasannya terdapat pesanan baru. Kata baru kedua yang diucapkan oleh pramusaji memiliki makna terdapat pembeli yang baru datang. Hal ini terlihat dari tindak tutur "Bim baru ya tolong diorder!". Kata baru yang kemudian terdapat kata penjelasan diorder atau dipesan menunjukkan bahwa terdapat pembeli baru yang harus segera diorder. Hal itupun terlihat pada peristiwa dimana parmusaji yang dimaksud kemudian melayani pembeli yang baru datang.

Selain kata baru, ditemukan pula kata Bukhori yang memiliki arti bukan sapaan nama orang bernama Bukhori, melainkan nama sebuah pondok pesantren, yakni ada order pesanan dari Pondok Pesantren Imam Bukhori. Kemudian dalam Tabel 2 ada kalimat 22 nasi satu, memiliki arti perubahan makna bahwasannya pada meja pelanggan nomer 22 terdapat pesanan tambahan yaitu nasi satu. Kata biang di sini bukan berarti kepala atau pimpinan suatu kelompok, akan tetapi perubahan makna pada wujud istilah resep bumbu. Register perubahan makna yang terakhir ialah blong. Blong biasanya diartikan sebagai sesuatu yang tidak berfungsi, namun dalam peristiwa tuturan ini blong diartikan sebagai perubahan makna untuk data pemasukan dan penjualan ayam.

Bentuk register perubahan makna berfungsi untuk memberi kode, memudahkan pesan untuk diterima antarpramusaji. Fungsi lainnya bertujuan untuk merahasikan kode yang ada pada rumah makan Ayam Penyet Surabaya. Register perubahan makna antarpramusaji rumah makan Ayam Penyet Surabaya tidak begitu banyak seperti register berbentuk akronim. Dari peristiwa yang tercatat diperoleh analisis yang dilakukan peneliti terdapat bentuk register perubahan makna pada rumah makan tersebut, yaitu baru yang artinya terdapat pesanan baru atau pembeli yang baru datang, Bukhori yang berarti adanya 
pesanan Pondok Pesantren Imam Bukhori, 22 nasi satu yang bermakna meja 22 tambah pesanan nasi satu, biang yang bermakna resep bumbu, dan blong yang artinya data pemasukan dan penjualan ayam.

\section{Bentuk Register Sindiran}

Dalam penelitian ini register sindiran merupakan bahasa yang digunakan untuk memberikan kode secara halus sesama pramusaji mengenai pekerjaan. Kode halus yang diberikan antarpramusaji dilakukan dengan nada candaan, sehingga tidak menimbulkan adanya rasa marah atau emosi. Tabel 3 merupakan data terkiat dengan register sindiran pada rumah makan Ayam Penyet Surabaya.

Tabel 3

Bentuk Register Sindiran

\begin{tabular}{clll}
\hline No & \multicolumn{1}{c}{ Bentuk Register } & \multicolumn{1}{c}{ Kalimat } & \multicolumn{1}{c}{ Makna } \\
\hline I. & Meja 7 manggil-manggil & Duh, kok meja 7 manggil-manggil, ya dari tadi! & Diminta untuk clear up \\
2. & $\begin{array}{l}\text { Aku rung kerjo kok ket mau } \\
\text { (aku belum kerja dari tadi) }\end{array}$ & $\begin{array}{l}\text { Kene, aku wae. Opo iki! Aku rung kerjo ket mau! } \\
\text { (Sini aku saja! Aku belum kerja dari tadi!) }\end{array}$ & $\begin{array}{l}\text { Menyindir teman nya yang } \\
\text { dari tadi leha-leha. }\end{array}$ \\
3. & Meja 3 bersih i to! & Ya Allah meja 3 bersih, i to? Duh...duh... & $\begin{array}{l}\text { Memberitahu jika meja 3 } \\
\text { kotor dan perlu dibersihkan } \\
\text { 4. }\end{array}$ \\
$\begin{array}{lll}\text { Lantai ne bersih (lantainya } \\
\text { bersih) }\end{array}$ & $\begin{array}{l}\text { Yang sif siang mana ini! Lantai ne bersih banget, ya } \\
\text { hahaha. }\end{array}$ & $\begin{array}{l}\text { Meminta pramusaji yang } \\
\text { masuk siang untuk menyapu } \\
\text { lantai yang kotor. }\end{array}$ \\
\hline
\end{tabular}

\section{Peristiwa 3}

Terdapat empat bentuk register sindirian yang ditemukan pada pramusaji di rumah makan tersebut. Berikut merupakan salah satu contoh percakapan antarpramusaji yang menggunakan register bahasa berbentuk sindiran.
Kasir
: "Duh, kok meja 7 manggil-manggil, ya dari tadi! Hahaha."
Pramusaji I
: "Iya iya, ngono e lo hahaha." (Iya iya, gitu aja lo hahaha)
Pramusaji 2
: "Berangkat!"
Pramusaji 3
: "Kene aku wae. Opo iki! Aku rung kerjo ket mau!"(Sini aku saja.Apa ini! Aku belum bekerja dari tadi!)
Pramusaji 2
: "Halah-halah paham maksudmu, Bil.Hahaha"
Pramusaji 3
:"Ya Allah meja 3 betsih i to? Duh...duh... nak sekalian di lap piye, to?" (Ya
Pramusaji 2
Allah meja 3 bersih i to? Duh... duh... kalau sekalian dibersihin gimana, sih?)
Pramusaji 3
: "Berangkat!"
Pramusaji 4
: "Ehem, yang sif siang mana ini! Lantai ne bersih banget, ya. Hahaha."
: "Krungu, ya krungu aku. Wkwk." (Dengar, ya dengar aku)

Pada proses komunikasi percakapan antar pelayan di atas menggunakan narasi yang santai dengan nada bercanda. Bentuk istilah yang digunakan ialah sindiran. Seperti pada penelitian sebelumnya Inderasari \& Oktavia (2018) "pemakaian register bahasa kru bus AKAP di Terminal Tirtonadi Surakarta” dalam hasil penelitian ditemukan adanya penciptaan kata baru dengan makna baru yang memiliki banyak arti dalam ranah bahasa, sehingga banyak arti tersebut mengakibatkan makna yang berbeda. Bentuk penciptaan kata baru ini juga memunculkan makna baru yang fungsinya digunakan untuk menyidir. Tindak tutur ini dilakukan ketika rumah makan dalam keadaan lenggang atau tidak terlalu ramai karena pembeli sudah meninggalkan tempat. Beberapa meja terlihat kotor karena baru saja selesai digunakan pembeli untuk makan. Kemudian pramusaji melakukan percakapan tersebut dan mereka beranjak untuk membersihkan meja yang kotor. Ternyata tindak tutur tersebut memberikan kode pada pramusaji untuk membersihkan meja yang kotor dengan sindiran. Misalnya pada kalimat "Duh, kok meja 7 manggil-manggil, ya dari tadi! hahaha", yang berarti menyindir pramusaji lain untuk membersaihkan meja yang kotor atau clear up. Kemudian pada kalimat "Ya Allah meja 3 bersih i to? 
Duh...duh... nak sekalian di lap piye, to?" (Ya Allah meja 3 bersih i to? Duh... duh... kalau sekalian dibersihin gimana, sih?) kalimat ini juga memiliki makna yang sama dengan kalimat sebelumnya, yakni meja yang dimaksud kotor dan perlu dibersihkan. Selanjutnya yaitu kalimat "Kene aku wae. Opo iki! Aku rung kerjo ket mau!" (sini aku saja. Apa ini! Aku belum bekerja dari tadi!) yang berarti menyindir teman kerjanya yang sedari tadi leha-leha. Tentu dalam pengucapannya tidak ada yang merasa sakit hati, hal ini karena meraka melakukannya dengan candaan dan tingkah laku yang jahil. Kalimat terakhir yang menyatakan register berupa sindiran terlihat pada kalimat "Ehem... yang jaga siang mana ini! Lantai-ne bersih banget, ya hahahaha..." kalimat ini bermakna bahwasannya meminta pramusaji yang masuk siang untuk menyapu lantai yang kotor. Hal ini memang sudah biasa dilakukan ketika adanya pergantian sif antara karyawan yang masuk pagi dan sore, maka karyawan yang masuk siang menyapu lantai karena sudah kotor.

Dari penjelasan di atas dapat dikatakan bahwa karakteristik register bahasa pada rumah makan Ayam Penyet Surabaya antarpramusaji memiliki register yang berbentuk sindiran. Sindiran di sini dilakukan untuk saling mengingatkan satau sama lain agar saling membantu dalam bekerja dan tidak ada yang leha-leha ketika temannya bekerja. Bentuk sindiran yang dilakukan masih dalam taraf bercanda atau tidak adanya niat untuk menyakiti. Hal ini terlihat dari tindak tutur antar pramusaji yang menggunakan nada santai, bercanda, dan ketawa satu sama lain.

\section{Bentuk Register Tunggal}

Register tunggal merupakan bahasa yang dihasilkan oleh sekelompok tertentu dengan wujud bahasanya yang utuh. Pada penelitian ini register berbentuk tunggal ditemukan dari kata baru, bukhori, blong, dan biang sebagaimana Tabel 4.

Tabel 4

Bentuk Register Tunggal

\begin{tabular}{|c|c|c|c|}
\hline No & $\begin{array}{c}\text { Bentuk } \\
\text { Register }\end{array}$ & Kalimat & Makna \\
\hline I. & Baru & Baru guys! & Terdapat pesanan baru atau ada pembeli yang baru datang. \\
\hline 2. & Bukhori & Ada pesenan Bukhori, gak? & Pesanan makanan dari Pondok Pesantren Imam Bukhori. \\
\hline 3. & Blong & Eh, Rin ambilin blong di laci! & Stok data pemasukan dan pengeluaran ayam. \\
\hline 4. & Biang & $\begin{array}{l}\text { Biang sambalnya butuh berapa? } \\
\text { Biang TK-nya masih nggak? }\end{array}$ & Resep bumbu. \\
\hline
\end{tabular}

Register tunggal merupakan wujud bahasa yang digunakan sebagai pemendekan yang keadaannya sempurna atau dapat berdiri sendiri tanpa adanya imbuhan afiksasi. Seperti pada penelitian sebelumnya Inderasari \& Oktavia (2018) "pemakaian register bahasa kru bus AKAP di Terminal Tirtonadi Surakarta" dalam hasil penelitian ditemukan bahwa register tunggal sifatnya utuh berdiri sendiri tanpa afikasi apapun seperti pada tuturan yo, lolos, angkat, mlayu semua digunakan kru bus untuk memberikan informasi dan ajakan. Tindak tutur register tunggal ini dilakukan ketika pramusaji menulis pesanan dari pembeli di buku order, kemudian koki melihat pesanan tersebut sambil mengangguk tanda bahwa paham pesanan yang ada. Seperti pada kata baru yang berarti terdapat pesanan masuk yang ditulis atau ada pembeli yang baru datang. Misalnya pada ujaran "Baru guys!". Ujaran ini memberi kode bahwa terdapat pesanan baru yang harus dikerjakan.

Kata Bukhori berarti menunjukkan adanya kode pesanan dari Pondok Pesantren Imam Bukhori yang harus dikerjakan, seperti pada ujaran "Ada pesenan Bukhori, gak?" Kata biang berarti resep bumbu rahasia yang digunakan pada rumah makan Ayam Penyet Surabaya yang ditemukan pada ujaran "Biang sambalnya butuh berapa?" dan juga "biang TK-nya masih nggak?". Sedangkan kata Blong memiliki makna data pemasukan dan penjualan ayam pada rumah makan tersebut, misalnya pada ujaran "Eh, Rin ambilin blong di laci"." Dari keempat bentuk register tunggal yang ditemukan kebanyakan berupa register dari perubahan makna. 


\section{Bentuk Register Kompleks}

Register kompleks memiliki makna sebaliknya dari register tunggal. Artinya wujud bahasa yang dihasilkan tidak dapat berdiri sendiri dan harus adanya afiksasi. Tabel 5 merupakan data dari register kompleks antar pramusaji pada rumah makan Ayam Penyet Surabaya.

Tabel 5

Bentuk Register Kompleks

\begin{tabular}{ccll}
\hline No & Bentuk Register & \multicolumn{1}{c}{ Kalimat } & \multicolumn{1}{c}{ Makna } \\
\hline I. & 3I sambal satu & 3I sambal satu, ya Bima! & Meja 3 I terdapat pesanan tambahan yakni sambal. \\
2. & $\begin{array}{c}\text { Meja I8 } \\
\text { manggil-manggil! }\end{array}$ & Bima,meja I8 manggil-manggil, ya! & Kode untuk membersihkan meja I8 yang kotor. \\
3. & $\begin{array}{c}\text { Meja I2 bersih } \\
\text { sekali... }\end{array}$ & Ya Allah meja I2 bersih sekali. Haha. & $\begin{array}{l}\text { Memberitahu jika meja I2 kotor dan perlu } \\
\text { dibersihkan. }\end{array}$ \\
4. & Lantai ne bersih & $\begin{array}{l}\text { Gimana ini lantai ne kok bersih! Yang } \\
\text { siang mana, ya. }\end{array}$ & $\begin{array}{l}\text { Meminta pramusaji yang masuk sif siang untuk } \\
\text { menyapu lantai yang kotor. }\end{array}$ \\
\hline
\end{tabular}

Jika register tunggal dapat berdiri sendiri tanpa adanya imbuhan afiksasi, maka register kompleks ialah bukan wujud kata yang dapat berdiri sendiri. Atau dapat dikatakan sebagai kalimat yang tidak utuh atau tidak sempurna, perlu adanya afiksasi sehingga kata dalam kalimat tersebut menjadi bermakna. Senada dengan penelitian yang dilakukan oleh Pramitasari (2014) dengan judul penelitian "Register pelaku industri batik di Kota Pekalongan: Kajian sosiolinguistis" ditemukan hasil dari pembahasan adanya register berbentuk kata kompleks mencakup register berbentuk frasa, kata majemuk, bentuk reduplikasi, dan bentuk berafiks. Berdasarkan kategori gramatika, ditemukan register berbentuk nomina, verba, dan numeralia. Penelitian yang relevan lain sebelumnya mengenai "pemakaian register bahasa kru bus AKAP di Terminal Tirtonadi Surakarta” yang dilakukan Inderasari dan Oktavia (2018) ditemukan register berbentuk kompleks saja. Pada register kompleks memiliki pengertian sebaliknya dengan register tunggal, sehingga register kompleks tidak dapat berdiri sendiri atau membutuhkan afiksasi. Salah satu contoh kalimatnya adalah iki perpal Solo, menyatakan jika bus ini tidak melakukan perjalanan sampai Jogja, namun hanya sampai Solo saja, kemudian kata becok mau nyalip, yang berarti terdapat armada bus lain yang berhasil mendahului bus yang dikendarai dengan kode dari kru bus terhadap sopir bus. Artinya register kompleks juga memberikan isyarat atau kode, namun kode tersebut tidak hanya ditujukan pada sopir bus seperti yang ditemukan dalam register tunggal, register kompleks ini juga terdapat kode yang ditujukan pada penumpang.

Tindak tutur dalam tabel 5 ditemukan data pola register komplek yang dilakukan pramusaji tentu bertujuan untuk memberikan kode kepada pramusaji lain agar memahami maksud yang diharapkan. Pada ujaran "3I sambal satu ya Bima!" yang berarti pramusaji memberikan kode kepada pramusaji lain untuk mengambilkan pesanan tambahan yaitu berupa sambal satu untuk meja $3 \mathrm{I}$. Kemudian ditemukan pula ujaran "Bima, meja I8 manggil-manggil, yal" berarti memberikan kode pada pramusaji bahwasannya meja I8 kotor dan segera untuk dibersihkan. Ujaran selanjutnya, yaitu " $Y a$ Allah meja I2 bersih sekali.. haha!" berarti meminta untuk membersihkan meja I2 yang sebenarnya kotor. Ujuaran terakhir yang termasuk dalam register kompleks ialah pada kalimat "Gimana ini lantai ne kok bersih!! Yang siang mana ya...”. Ujuran ini memiliki makna meminta pramusaji yang masuk siang untuk menyapu lantai yang kotor. Pada bentuk register kompleks ini banyak ditemukan data atau hasil dari bentuk register sindiran dan juga perubahan makna.

Penelitian yang relevan sebelumnya mengenai "pemakaian register bahasa kru bus AKAP di Terminal Tirtonadi Surakarta” yang dilakukan Inderasari dan Oktavia (2018) ditemukan register berbentuk kompleks saja. Pada register kompleks memiliki pengertian sebaliknya dengan register tunggal, sehingga register kompleks tidak dapat berdiri sendiri atau membutuhkan afiksasi. Salah satu contoh kalimatnya adalah iki perpal Solo, menyatakan jika bus ini tidak melakukan perjalanan sampai Jogja, namun hanya sampai Solo saja, kemudian kata becok mau nyalip, yang berarti terdapat armada 
bus lain yang berhasil mendahului bus yang dikendarai dengan kode dari kru bus terhadap sopir bus. Artinya register kompleks juga memberikan isyarat atau kode, namun kode tersebut tidak hanya ditujukan pada sopir bus seperti yang ditemukan dalam register tunggal, register kompleks ini juga terdapat kode yang ditujukan pada penumpang.

Berbeda halnya dalam penelitian ini, tidak hanya register tunggal dan kompleks, namun juga ada register akronim, perubahan makna, dan sindiran. Register tunggal pada penelitian ini memiliki karakteristik yang berbeda. Kata yang digunakan berperan sebagi kode antar pramusaji pada rumah makan atau sebagai wujud kata yang dapat berdiri sendiri. Misalnya pada kata baru yang memiliki makna terdapat pesanan yang baru datang atau pembeli yang baru datang. Selain itu, register tunggal yang ditemukan dalam penelitian ini juga termasuk dalam register perubahan makna. Pada register kompleks dalam penelitian ini juga memiliki karakteristik yang berbeda dari penelitian sebelumnya. Pada register kompleks ini betujuan untuk memberikan sebuah kode antar pramusaji namun juga berfungsi sebagai sindiran antar pramusaji. Karena memang register kompleks pada penelitian ini termasuk pula dalam register sindiran dan perubahan makna, sehingga sudah jelas bila karakteristik register kompleks dalam penelitian ini adanya perubahan makna.

Karakteristik register akronim tentu dengan pemendekan atau singkatan dalam bahasa yang digunakan antar pramusaji, hal ini untuk memudahkan dan mempercepat pelayanan terhadap pembeli. Berbeda dengan register akronim, register perubahan makna bahasa yang digunakan antar pramusaji bertujuan untuk merahasiakan kode yang ada pada rumah makan. Selanjutnya karakteristik register sindiran yang bertujuan untuk menyindir mengenai pekerjaan antar pramusaji dengan nada jenaka. Jika pramusaji menggunakan register sindiran ini dalam berkomunikasi, maka tidak menimbulkan rasa emosi namun justru dengan komedi.

Temuan penelitian ini mengungkapkan karakeristik pemakaian register antarpramusaji rumah makan Ayam Penyet Surabaya serta makna dan fungsi register tersebut digunakan. Variasi register pramusaji lebih memiliki banyak pola dibanding register kru bis AKAP dalam moda transportasi di terminal Tirtonadi Surakarta yang pernah diteliti. Pada penelitian sebelumnya variasi register yang digunakan pada kru bis AKAP ditemukan adanya register tunggal dan kompleks saja sesuai dengan fungsi dan maksud komunikasi register tersebut muncul, sedang kemenarikan hasil penelitian ini bahwa adanya pola-pola akronim atau singkatan, register pergeseran atau perubahan makna pada kata, register berupa sindiran dan register tunggal.

\section{SIMPULAN}

Berdasarkan hasil penelitian dan pembahasan yang dilakukan tentang analisis karakeristik pemakaian register antarpramusaji rumah makan Ayam Penyet Surabaya, disimpulkan sebagai berikut. Pertama, karakteristik yang ditemukan adalah adanya pola akronim atau singkatan. Seperti PAPN, $P A G N, P A P K$, dan $P A G K$ baik yang digunakan dalam tuturan lisan dan tulis dengan jumlah pemakaian terbanyak sejumlah 32 akronim yang digunakan pada menu yang ada pada rumah makan. Register akronim berfungsi sebagai sarana mempersingkat menu pada rumah makan. Kedua, register pergeseran atau perubahan makna pada kata. Misalnya pada kata baru, yang secara leksikal memiliki arti sesuatu yang belum lama dibeli, menjadi adanya pesanan yang baru datang atau adanya pembeli yang datang untuk memesan, dan menyatakan keterangan waktu. Fungsi register perubahan makna sendiri digunakan untuk merahasikan kode yang terdapat pada rumah makan tersebut. Karakteristik ketiga register berupa sindiran. Contohnya kalimat meja 7 manggil-manggil, aku rung kerjo kok ket mau (aku belum kerja dari tadi), meja 3 bersih i to!, lantai ne bersih (lantainya bersih). Register sindiran berfungsi mengkode antar sesama pramusaji secara humor mengenai pekerjaan. Pada karakteristik ini terdapat pula penggunaan bahasa Jawa. Selanjutnya karakteristik keempat register tunggal. Seperti kata baru, Bukhori, biang, blong. Selain itu, karakteristik ini banyak ditemukan pada bentuk register perubahan makna. Karakteristik yang kelima register kompleks seperti, 3 I sambal satu, meja I8 manggil-manggil, meja I2 bersih sekali, dan 
lantaine bersih. Karakteristik register kompleks ini banyak ditemukan pada register sindiran dan juga perubahan makna dan wujud bahasanya tidak dapat berdiri sendiri.

Adapun relevansi hasil penelitian dapat dijadikan sebagai pengembangan bahan ajar kebahasaan tentang keragaman variasi register yang berkembang di masyarakat. Bagi masyarakat umum berfungsi untuk mengenal kekhasan register antarpramusaji di sebuah rumah makan. Penelitian ini dapat dijadikan referensi untuk penelitian lebih lanjut terkait karakteristik register yang ditemukan pada pramusaji yang meliputi (I) bentuk register akronim, (2) perubahan makna, (3) sindiran, (4) tunggal, dan (5) kompleks dalam kajian sosiolinguistik.

\section{UCAPAN TERIMA KASIH}

Penulis mengucapkan terima kasih kepada Program Studi Tadris Bahasa Indonesia yang telah membawa penulis untuk melakukan penelitian ini melalui mata kuliah Sosiolinguistik. Selain itu, penulis juga mengucapkan terima kasih kepada para pramusaji dan pengelola Rumah Makan Ayam Penyet Surabaya cabang Ngangkruk atas kerjasama dalam keterbukaan ketersediaan data serta seluruh pengelola jurnal Kembara.

\section{DAFTAR PUSTAKA}

Ardi, H. (2017). Penerjemahan register militer pada subtitling film" The Great Raid”. Lingua Didaktika: Jurnal Bahasa dan Pembelajaran Bahasa, 7(I), 29-37. doi: https://doi.org/I0.24036/1d.v7iI.3530

Atmahardianto, C. (2012). Register dalam situs komunitas dunia maya kaskus. (Skripsi), Universitas Sebelas Maret Surakarta Retrieved from https://digilib.uns.ac.id/dokumen/detail/25660/Register-dalam-Situs-Komunitas-DuniaMaya-Kaskus

Chaer, A., \& Agustina, L. (2010). Sosiolinguistik: Perkenalan awal. Jakarta: PT Rineka Cipta.

Damayanti. (2017). Register percakapan anggota kesatuan lalu lintas Polresta Pontianak: Kajian sosiolinguistik. $\quad$ Aksara, $29(\mathrm{I}), \quad$ I03-II6. doi: https:/ / doi.org/I0.29255/aksara.v29i1.I04.I03-II6

Damayanti. (2018). Register dalam komunikasi waria di Kembang Kuning Surabaya. SeBaSa: Jurnal Pendidikan Bahasa dan Sastra Indonesia, I(2), I42-I52. Retrieved from http://www.ejournal.hamzanwadi.ac.id/index.php/sbs/article/view/I042/635

Eriyanti, R. W. (2017). Koherensi pertanyaan guru pada pembelajaran. KEMBARA: Jurnal Keilmuan Bahasa, Sastra, dan Pengajarannya, 2(I), 77-89. doi: https://doi.org/I0.22219/kembara.v3iI.438I

Faizun, A. (2015). Penggunaan umpatan dalam bahasa Madura. KEMBARA: Jurnal Keilmuan Bahasa, Sastra, dan Pengajarannya, I(I), I I-25. doi: https://doi.org/I0.222I9/kembara.vIiI.2327

Firmansyah, M. B. (20I7). Representasi bahasa humor dalam acara stand up comedy di Metro TV. KEMBARA: Jurnal Keilmuan Bahasa, Sastra, dan Pengajarannya, 2(2), 195-202. doi: https:/ / doi.org/I0.22219/kembara.v2i2.4004

Giyoto, G. (2020). Sosiolinguistik dan media digital. Yogyakarta: CV. Gerbang Media Aksara.

Hadi, I. (2017). Register pedagang buah: Studi pemakaian bahasa kelompok profesi di Kota Padang. Metalingua: Jurnal Penelitian Bahasa, I5(I), 25-40. doi: http://dx.doi.org/I0.26499/metalingua.vI5iI.I52

Hermoyo, R. P. (2015). Register pekerja terminal petikemas Surabaya. Stilistika: Jurnal Pendidikan Bahasa dan Sastra, 8(2), 48-67. doi: http:/ / dx.doi.org/I0.30651/st.v8i2.58

Hilmiati, N. (20I2). Bentuk fatis bahasa Sasak. Mabasan, 6(2), 18-26. doi: https://doi.org/I0.26499/mab.v6i2.226

Holmes, J. (1992). An introduction to sociolinguistics. Atalanta: Routledge. 
Inderasari, E., \& Oktavia, W. (2018). Pemakaian register bahasa kru bus AKAP di Terminal Tirtonadi Surakarta (kajian sosiolinguistik). Dialektika: Jurnal Bahasa, Sastra, dan Pendidikan Bahasa dan Sastra Indonesia, 5(2), I59-I78. doi: https://doi.org/I0.I5408/dialektika.v5i2.78I5

Luthfiyanti, L., \& Kasmilawati, I. (2018). Register bidan di Puskesmas Kecamatan Sungai Tabuk Kabupaten Banjar. STILISTIKA: Jurnal Bahasa, Sastra, dan Pengajarannya, 3(I). doi: https://doi.org/I0.33654/sti.v3iI.508

Malabar, S. (20I5). Sosiolinguistik (M. Mirnawati Ed.). Gorontalo: Ideas Publishing.

Miles, M. B., \& Huberman, A. M. (1994). Qualitative data analysis: An expanded sourcebook. Los Angeles: Sage.

Mujianto, G. (20I8). Piranti Kohesi dalam wacana tulis guru SMA/SMK Muhammadiyah Kabupaten Malang KEMBARA: Jurnal Keilmuan Bahasa, Sastra, dan Pengajarannya, 3(2), 210-233. doi: https://doi.org/I0.22219/kembara.v3i2.5162

Pramitasari, A. (20I4). Register pelaku industri batik di Kota Pekalongan: Kajian sosiolinguistis. Seloka: Jurnal Pendidikan Bahasa dan Sastra Indonesia, 3(2), I I0-I I4.

Prasetya, T. (2017). Kosakata sehari-hari kelompok transeksual di Kecamatan Pakis Kabupaten Malang. KEMBARA: Jurnal Keilmuan Bahasa, Sastra, dan Pengajarannya, 2(I), 98-I09. doi: https://doi.org/10.22219/kembara.v2iI.4048

Rahmah, Y., Bahry, R., \& Mahmud, S. (2017). Bahasa register kelompok petani kopi di dataran tinggi Gayo. JIM Pendididikan Bahasa dan Sastra Indonesia, 2(4), 400-4I2. Retrieved from http://www.jim.unsyiah.ac.id/pbsi/article/view/700I/3122

Ramendra, D. (2013). Variasi pemakaian bahasa pada masyarakat tutur Kota Singaraja. Jurnal Ilmu Sosial dan Humaniora, 2(2), 275-287. doi: http://dx.doi.org/I0.23887/jishundiksha.v2i2.2I85

Senjaya, A., Solihat, I., \& Riansi, E. S. (2018). Kajian sosiolinguistik pemakaian variasi bahasa ken (cant) oleh para pengemis di lingkungan lampu merah Kota Serang Provinsi Banten. Jurnal Membaca Bahasa dan Sastra Indonesia, 3(2), III-II8. doi: http://dx.doi.org/I0.30870/jmbsi.v3i2.5224

Setianingsih, E. (2013). Register nelayan di Pantai Depok Parangtritis Kretek Bantul. (Skripsi), Universitas Negeri Yogyakarta, Yogyakarta. Retrieved from https:/ / eprints.uny.ac.id/25822/I/Endri\%20Setianingsih\%2006205244I20.pdf

Setiawan, F. (2018). Fungsi Instrumental pada jargon komunitas kru bus jurusan Jember-banyuwangi. KEMBARA: Jurnal Keilmuan Bahasa, Sastra, dan Pengajarannya, 4(I), 48-55. doi: https://doi.org/I0.22219/kembara.v4iI.5458

Shahamatun, A. D. (20I4). Penggunaan register profesi bidan di klinik dan rumah bersalin di Delta Mutiara Sukodono, Sidoarjo. Skriptorium, 2(2), I-I2. Retrieved from http://journal.unair.ac.id/downloadfull/SKRIPTORIUM7828-60ba476528fullabstract.pdf

Subroto, E. (2007). Pengantar metode penelitian linguistik struktural. Surakarta: UNS Press.

Sudaryanto, M. (2013). Register anak jalanan Kota Surakarta. (Skripsi), Universitas Sebelas Maret Surakarta. Retrieved from https://digilib.uns.ac.id/dokumen/detail/29420/Register-AnakJalanan-Kota-Surakarta

Sugiyono, P. (20I4). Metode penelitian kuantitatif, kualitatif, dan R\&D. Bandung: Alfabeta.

Tutik, A. D., Fitriani, N., \& Inderasari, E. (2020). Variasi dan fungsi ragam bahasa pada iklan dan slogan situs belanja online Shopee. Imajeri: Jurnal Pendidikan Bahasa dan Sastra Indonesia, 2(2), I37-I48. doi: https://doi.org/I0.29405/imj.v2i2.58

Utomo, D. W. (20I4). Register laporan pandangan mata komentator sepakbola (Sebuah kajian sosiolinguistik). Jurnal Sasindo UNPAM, I(I), I6-33. doi: http://dx.doi.org/10.32493/sasindo.vIiI.\%25p

Widodo, P. (2000). Register pemanduan wisata. Jurnal Humaniora, I2(3), 295-305. 
Wijana, I. D. P. (2019). Indonesian train naming system. Paper presented at the Prosiding Seminar Nasional Pertemuan Ilmiah Bahasa dan Sastra Indonesia (PIBSI) Ke-4I, Surakarta: 2I-22 Agustus 2019.

Winanto, Y. (2014). Register sepak bola acara Lensa Olahraga di ANTV. (Skripsi), Universitas Muhammadiyah Surakarta, Surakarta. Retrieved from http:// eprints.ums.ac.id/id/eprint/29690

Yuanita, A. (2019). Bentuk dan distribusi ungkapan fatis bahasa Indonesia siswa kelas VI sekolah dasar. Jurnal Pena Indonesia, 5(2), I29-I39. doi: http:/ / dx.doi.org/I0.26740/jpi.v5n2.pI29-I39 